\title{
Effects of a single low-intensity resistance exercise session on lipid peroxidation of untrained male students
}

\author{
Mohammad Hossein Sepehri, Masoud Nikbakht, Abdolhamid Habibi, Mustafa Moradi \\ Department of exercise physiology, Faculty of Physical Education and sports sciences, Shahid Chamran University, Ahvaz, Iran ${ }^{1}$ \\ Email address: \\ hosseinsepehri63@gmail.com (M. H. Sepehri),moradi0899@gmail.com (M. Moradi)
}

\section{To cite this article:}

Mohammad Hossein Sepehri, Masoud Nikbakht, Abdolhamid Habibi, Mustafa Moradi.Effects of a Single Low-Intensity Resistance Exercise Session on Lipid Peroxidation of Untrained Male Students. American Journal of Sports Science. Vol. 2, No. 4, 2014 , pp. 87-91. doi: 10.11648/j.ajss.20140204.13

\begin{abstract}
Introduction: The aim of the present study was to examine the effects of a single bout of resistance exercise with low intensity of oxidative stress on male students who did not do any regular sports whatsoever. Materials and Methods: For this purpose, 16 untrained subjects with a mean age of $24.40 \pm 1.7$ years, height $176 \pm 6.83 \mathrm{~cm}$, weight $69.89 \pm 6.6$ and BMI $22.89 \pm 0.89 \mathrm{~kg} / \mathrm{m}^{2}$, were studied pre and post a low intensity resistance exercise. The exercise protocol involved Scott and leg stretching for the lower limbs and stretch underarm and chest press for the upper limbs. The subjects performed each exercise 3 times (one minute rest between sets). The low- intensity test was performed in $25-30 \%$ of one repetition maximum (25 to 30 reps). Malondialdehyde (MDA) as an index of lipid peroxidation was measured before exercise, immediately after and 6 and $24 \mathrm{~h}$ after exercise. Results: Our data were analyzed using one factor repeated measures. Our results revealed a significant increase in MDA in response to low intensity resistance exercise at pre and post exercise time points in untrained subjects $(\mathrm{P}<0.05)$. The peak increase was observed at immediately post-exercise time point $(\mathrm{P}<0.0001, \mathrm{~F}=98.36)$ and the measures returned to resting values 24 hours after the test. Conclusion: Overall, resistance exercise, even though low-intense one appears to increase resistance oxidative stress.
\end{abstract}

Keywords: Resistance Exercise, Oxidative Stress, Free Radicals, Malondialdehyde

\section{Introduction}

Production of reactive oxygen and nitrogen species (RONS), including Singlet Oxygen $(\mathrm{O})$, Superoxide $\left(\mathrm{O}_{2}^{-}\right)$, Hydrogen peroxide $\left(\mathrm{H}_{2} \mathrm{O}_{2}\right)$, Hydroxyl $(\mathrm{OH})$, Peroxynitrite $\left(\mathrm{ONO}_{2}\right)$, and Nitric Oxide (NO), is a result of natural cellular metabolism, which seems to rise in mental and physical stress (sen et al., 1994). Adequate intensity of both aerobic and anaerobic exercises is followed by a rise in the oxidation of macromolecules (Bloomer et al., 2006). In anaerobic exercises (e.g. resistance, isometric), there are other pathways of RONS production, including ischemiareperfusion, xanthine and NADPH oxidize production, prostanoid metabolism, phagocytosis respiratory burst activity, disruption of iron-containing proteins, and changes in calcium homeostasis(Bloomer et al., 2006; Bloomer et al., 2004). The RONS production through these pathways may, to some extent, result from eccentric muscle activities, which will damage muscle tissue (McHugh et al., 1999). Resistance exercises have been proved to have many advantages, including weight control, prevention of osteoporosis, improvement of cardiovascular risk factors, and injury prevention (Dinubile et al., 1991; Verrill et al., 1996). They, furthermore, stimulate hormonal responses, which influence muscle growth and regeneration (Kraemer et al., 2007). However, too much resistance exercise may cause oxidative stress and cell damage (Liu et al., 2005). Only two hypotheses propose that resistance exercises can contribute to an increased formation of free radicals in active muscles. One hypothesis addresses the damage induced by ischemiareperfusion (McBride et al., 1998). Severe muscle contractions may induce a temporary decline in blood circulation and available oxygen, as well as, the resulting ischemia-reperfusion. Subsequent to contraction (muscle relaxation) and reperfusion, a huge load of extraordinary oxygen is produced, which results in the formation of $\mathrm{O}_{2}^{-}$ radicals. Mechanical pressure is another hypothesis for justifying the increased free radical production (Viitala et al., 2004). In particular, eccentric exercises tend to damage muscle tissue, as they maintain high levels of force. The 
resulting inflammation process triggers the production of free oxygen radicals. The significant increase in free radical production can, indirectly, be determined through measuring the produced lipid peroxidation, including plasma malondialdehyde (MDA) (Halliwell and Chirico, 1993). The majority of studies conducted in this area have focused on the effects of exercise on aerobic activities (Maughan et al., 1989; Child et al., 1999; Kanter et al., 1988; Kanter et al., 1993; Dillard et al., 1978; Pincemail et al., 1990; Sumida et al., 1989), while, a limited number of studies has addressed resistance exercises and free radical formation (McBride et al., 1998; Güzel et al., 2007). Some studies (Sahlin et al., 1992; Saxton et al., 1994; Dixon, 2002) have shown that resistance exercises exert no influence on the rise of free radical formation. However, some other (McBride et al., 1998; Güzel et al., 2007), have observed a significant increase in the degrees of oxidative stress indices. Accordingly, the present study investigated the effects of low-intensity resistance exercise, in terms of volume and intensity, on oxidative stress in untrained male students.

\section{Method}

This semi-empirical applied study was conducted using a sample group including 8 untrained male students and four time points of testing. Subjects who did not do any regular resistance exercises in the past year were considered untrained. Cooperation, personal information, and medical background questionnaire was, first and foremost, filled by the participants. Any record of illness, skeletal and muscular injury, medication and supplement intake were taken into consideration in the questionnaire. The consent was obtained from the participants after they were informed of the stages of the study. Then, height and weight of each subject was measured and their body fat was estimated through bioelectrical impedance analysis (Inbody3/3, made in South Korea).The participants were introduced to 4 resistance exercises, including Scott and leg stretching for the lower limbs, and latissimusdorsi (underarm) stretch and chest press for the upper limbs, and their single repetition maximum, one week before commencing the study. The subjects underwent the tests with $25-30 \%$ of one repetition maximum (25 to 30 reps).

The subjects were asked to abstain from having protein foods, foods enriched in anti-oxidant substances including vitamins $\mathrm{C}$ and $\mathrm{E}$, doing intense sports activities, and taking medications which may affect the study results, three days prior to and one day after the tests were conducted.

Subjects commenced the resistance exercises in the morning, while fasting. After 15 minutes of warm-up and stretching exercise, the subjects performed the resistance exercise in 3 rounds. The recovery time was designated at 30 seconds for each round and 1 minute between different exercise stations.

Venous blood samples were taken from the forearm before the bout, immediately after the bout (within $1 \mathrm{~min}$.), and 6, 24 hours after the bout, which were preserved in the ice compartment until transferred to the laboratory. To collect plasma, prior to being centrifuged for 15 minutes at 1000 rounds per minute, the samples were left at room temperature for 30 minutes to coagulate. The plasma was, later on, divided into two equal parts and preserved at $-80{ }^{\circ} \mathrm{C}$. Samples were centrifuged for a second round after melt down and before the experiment. As for MDA measurement, Cusabio kit, manufactured by a Chinese-American Company, was used.

Descriptive Statistics was utilized to describe the data, and determine the mean and standard deviation. Repeated measures ANOVA and Bonferroni post hoc test were employed to compare MDA values before and after resistance exercise with low intensities in 4 intervals.

\section{Results}

The participants' physical characteristics including age, weight, height, and body mass index are presented in table 1.

Table 1. Descriptive findings of pertaining individual characteristics of the participants.

\begin{tabular}{llllll}
\hline Variable & Group & Mean & Standard Deviation & Min & Max \\
\hline Age $(\mathrm{Yrs})$ & Low Intensity & 25.43 & 2.14 & 22 & 28 \\
Weight $(\mathrm{Kg})$ & Low Intensity & 70.11 & 6.17 & 63 & 78 \\
Height $(\mathrm{Cm})$ & Low Intensity & 174 & 6.50 & 169 & 185 \\
BMI $\left(\mathrm{Kg} / \mathrm{m}^{2}\right)$ & Low Intensity & 22.74 & 0.85 & 21.60 & 24.10 \\
\hline
\end{tabular}

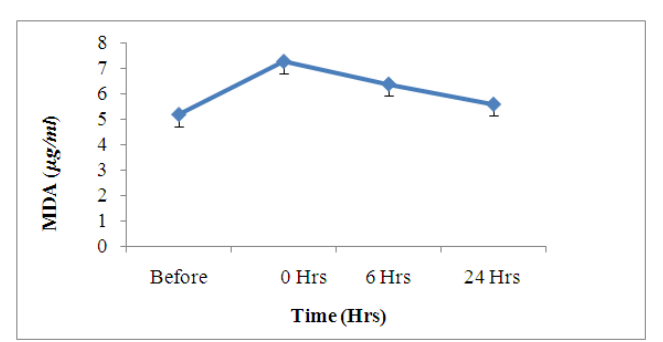

As shown in Figure 1, resting MDA index values were in normal expectations, and MDA levels raised immediately after cessation of the exercise $(\mathrm{P}<0.05)$. This sudden increase is significantly higher at 0 -hrs time point for the low resistance tests $(\mathrm{P}<0.05)$.MDA levels sharply declined 6 and 24 hours post-exercise time point, and returned to preexercise levels.

Figure 1. MDA value changes before and after a low intensity resistance exercise session 
Table 2. Repeated measures ANOVA indices for comparing MDA values before and after a low intensity resistance exercise session

\begin{tabular}{lllllll}
\hline Variable & Source of Changes & Sum of Squares & Degree of Freedom (df) & Mean Square & F & Significance Level \\
\hline MDA & Time & 17.72 & 3 & 5.90 & 98.36 & 0.001 \\
\hline
\end{tabular}

As shown by the results of Table 2, there is a significant intensity resistance exercise session $(\mathrm{P}<0.0001, \mathrm{~F}=98.36)$. difference between MDA values before and after a low

Table 3. Bonferroni post hoc test results for comparing MDA values before and after a low intensity resistance exercise session

\begin{tabular}{|c|c|c|c|c|c|c|}
\hline & Time & Mean $(\mu g / m l)$ & 1 & 2 & 3 & 4 \\
\hline 1 & Pretest & 5.18 & & $\begin{array}{l}\text { Mean Difference }=2.07 \\
\text { Significance Level }=0.001 *\end{array}$ & $\begin{array}{l}\text { Mean Difference }=1.18 \\
\text { Significance Level }=0.001 *\end{array}$ & $\begin{array}{l}\text { Mean Difference }=0.39 \\
\text { Significance Level }=0.12\end{array}$ \\
\hline 2 & $\begin{array}{l}\text { Immediately Post } \\
\text { Exercise }\end{array}$ & 7.26 & & & $\begin{array}{l}\text { Mean Difference }=0.89 \\
\text { Significance Level }=0.001 *\end{array}$ & $\begin{array}{l}\text { Mean Difference }=1.68 \\
\text { Significance Level }=0.001 *\end{array}$ \\
\hline 3 & 6 hrs Post Exercise & 6.37 & & & & $\begin{array}{l}\text { Mean Difference }=0.78 \\
\text { Significance Level }=0.05^{*}\end{array}$ \\
\hline 4 & 24 hrs Post Exercise & 5.58 & & & & \\
\hline
\end{tabular}

$*: \mathrm{P}<0.05$

Table 3 shows that the difference between MDA values pretest, and immediately and 6 hours after the exercise, as well as between 6 hours and 24 hours after the exercise was significant. The mentioned difference was only nonsignificant between pretest and 24 hours after the low intensity resistance exercise.

\section{Discussion and Conclusion}

The present study investigated the effects of low-intensity resistance exercise protocol on plasma lipid peroxidation index of untrained male students. The results revealed a significant increase in MDA, in response to Low intensity resistance exercise, before and immediately after the exercise $(\mathrm{P}<0.05)$; moreover, the results showed a significant difference in terms of MDA values, immediately after cessation of exercise $(\mathrm{P}<0.05)$.

Significance of time-related indices indicate that the MDA levels are different in all 4 measurement intervals $(\mathrm{P}<0.0001$, $\mathrm{F}=98.36$ ).

Numerous different exercise models have been implemented in order to recognize the effects of physical activity of different intensities on the various indices of oxidative stress (McBride et al., 1998; Viitala et al., 2004;Alessioet al., 2000;Atalayet al., 1996; Khannaet al., 1999;Lovlinet al., 1987;Simpsonet al., 2005). Resistance bouts are composed of repeated static muscle exercises, including concentric and eccentric muscular activities, considered as low and high intensity resistance exercises, respectively (Liu et al., 2005). A number of studies have investigated the oxidative stress induced by resistance exercises (McBride et al., 1998; Surmen-Gur et al., 1999).An increase in blood MDA was observed within 2 days after the resistance training protocol (McBride et al., 1998), while,6min after performing 20 eccentric-concentric repetitions involving knee extensors, no change was reported in blood MDA (Surmen-Gur et al., 1999). The difference in exercise protocols seems to account for the diverse results. In this study, low intensity resistance exercises led to a significant increase in lipid peroxidation, immediately after the bout $(\mathrm{P}<0.05)$. Maughan et al. (1989) maintain that peak MDA changes occur within 6 hours post-exercise, whereas, some studies have only investigated MDA levels immediately postexercise. Other studies, addressing the type of resistance exercise and free radical formation, did not report any increase in free radical formation (Sahlin et al., 1992, Saxton et al., 1994, Ortenblad et al., 1997). This may be due to lighter weights and lower muscle tissue activation.

Intense muscle contractions accompanied by resistance exercises may cause ischemia-reperfusion at active muscles. For skeletal muscles, free radicals act as mediators of the injury induced by ischemia-reperfusion. Similarly, Kanter et al. $(1988,1993)$ showed that plasma MDA levels maximized in low-resistance (LR) group immediately post-exercise, they also reported higher values in their high-resistance (HR) group, implying that different intensities may yield expectedly different results.

Results from this study are consistent with those reported by Guzel et al. (2007) and Go to et al. (2003), and inconsistent with results observed by Dixon (2002) and Goldfarb et al. (2008).Dickson's work (2002) lacked the required physiological threshold to stimulate free radical formation. Low lactate volume, low exercise volume, and lower muscle activation, which characterize the exercise protocol, may justify the mentioned contradiction. Accordingly, it seems that in order to be able to measure plasma MDA changes, higher threshold intensity is required for resistance exercises. As indicated by the results, full body resistance exercises stimulate oxidative stress to a certain level enough to trigger free radical formation (Güzel et al., 2007).In athletes, on the other hand, acquired adaptations decrease cell damages caused by exercise-induced free radical formation(Dixon, 2007).

According to the results, increased MDA production in 
response to Low intensity resistance exercise leads to a significant increase in the obtained values before and immediately after the exercise $(\mathrm{P}<0.05)$.

\section{References}

[1] Alessio, H.M., Hagerman, A.E., Fulkerson, B.K., Ambrose, J., Rice, R.E. and Wiley R.L. (2000) Generation of reactive oxygen species after exhaustive aerobic and isometric exercise. Medicine and Science in Sports and Exercise 32, 1576-1581.

[2] Atalay, M., Seene, T., Hanninen, O. and Sen C.K. (1996) Skeletal muscle and heart antioxidant defenses in response to sprint training. Acta Physiologic. Scandinavian 158, 129-134.

[3] Bloomer, R. J., \& Goldfarb, A. H. (2004). Anaerobic exercise and oxidative stress: a review. Canadian Journal of Applied Physiology, 29, 245-263.

[4] Bloomer, R. J., Falvo, M. J., Fry, A. C., Schilling, B. K., Smith, W. A., \& Moore, C. A. (2006). Oxidative stress response in trained men following repeated squats or sprints. Medicine and Science in Sports and Exercise, 38, 1436-1442.

[5] Child, R. B., Wilkinson, D. M, \& Fallowfield, J. L. (1999). Resting serum antioxidant status is positively correlated with peak oxygen uptake in endurance trained runners. Journal of Sports Medicine and Physical Fitness, 39,282-284.

[6] Dillard, C. J., Litov, R. E., Savin, W. M., Dumelin, E. E., \& Tappel, A. L. (1978). Effects of exercise, vitamin E, and ozone on pulmonary function and lipid peroxidation. J. Appl. Physiol, 45, 927-932.

[7] Dinubile, N.A. (1991) Strength training. Clinics in Sports Medicine 10, 33-62.

[8] Dixon, C. B. (2002). The effect of resistance training status on free radical production and muscle damage following an acute resistance exercise bout. $\mathrm{PhD}$, University of Pittsburgh.

[9] Goldfarb, A. H., Garten , R. S., Chee, P. D. M., Cho, C., Reeves, G. V., Hollander, D. B., . . . Kraemer, R. R. (2008). Resistance exercise eVects on blood glutathione status and plasma protein carbonyls: inXuence of partial vascular occlusion. Eur J Appl Physiol, 104, 813-819.

[10] Goto, C., Higashi, Y., Kimura, M., Noma, K., Hara, K., Nakagawa, K., . . . Nara, I. (2003). Effect of Different Intensities of Exercise on Endothelium-Dependent Vasodilation in Humans Role of Endothelium-Dependent Nitric Oxide and Oxidative Stress Circulation, 108(5), 530535.

[11] Güzel, N. A., Hazar, S., \& Erbas, D. (2007). Effects of different resistance exercise protocols on nitric oxide, lipid peroxidation and creatine kinase activity in sedentary males. Journal of Sports Science and Medicine 6(4), 417-422.

[12] Halliwell, B., \& Chirico, S. (1993). Lipid peroxidation: its mechanism, measurement, and significance. American Journal of Clinical Nutrition, 57(suppl), 715-724.

[13] Kanter, M. M., Lesmes, G. R., Kaminsky, L. A., Ham-Saeger, J. L., \& Nequin, N. D. (1988). Serum creatine kinase and lactate dehydrogenase changes following an eighty kilometer race. European Journal of Applied Physiology, 57, 60-63.
[14] Kanter, M.M., Nolte, L.A. and Holloszy, J.O. (1993) Effects of an antioxidant mixture on lipid peroxidation at rest and post exer-cise. Journal of Applied Physiology 74, 965-969.

[15] Khanna, S., Atalay, M., Laaksonen, D.E., Gul, M., Roy, S. and Sen, C.K. (1999) Alpha-lipoic acid supplementation: tissue glu-tathione homeostasis at rest and after exercise. Journal of Applied Physiology 86, 1191-1196.

[16] Kraemer, W. J., \& Ratamess, N. A. (2005). Hormonal responses and adaptations to resistance exercise and training. Sports Med, 35, 339-336.

[17] Liu, I. F., Chang, W. Y., Chan, K. H., Tsai, W. Y., Lin, C. L., \& Hsu, M. C. (2005). Blood lipid peroxides and muscle damage increased following intensive resistance training of female Weightlifters. Annals of the New York Academy of Science 1042, 255-261.

[18] Liu, I. F., Chang, W. Y., Chan, K. H., Tsai, W. Y., Lin, C. L., \& Hsu, M. C. (2005). Blood lipid peroxides and muscle damage increased following intensive resistance training of female Weightlifters. Annals of the New York Academy of Science 1042, 255-261.

[19] Lovlin, R., Cottle, W., Pyke, I., Kavanagh, M. and Belcastro, A.N. (1987). Are indices of free radical damage related to exercise in-tensity? European Journal of Applied Physiology $56,313-316$.

[20] Maughan, R., Donnellly, A.E., Gleeson, M., Whiting, P.H., Walker, K.A. and Clough, P.J. (1989) Delayed onset muscle damage and lipid peroxidation in man after a downhill run. Muscle \& Nerve 12, 332-336.

[21] McBride, J. M., Kraemer, W. J., \& Triplett-McBride, T. (1998). Effect of resistance exercise on free radical production. Med Sci Sports Exere, 30, 67-72.

[22] McHugh, M. P., Connolly, D. A., Eston, R. G., \& Gleim, G. W. (1999). Exercise-induced muscle damage and potential mechanisms for the repeated bout effect. Sports Medicine, 27(157-170).

[23] Ortenblad, N., Madsen, K., \& Djurhuus, M. S. (1997). Antioxidant status and lipid peroxidation after short-term maximal exercise in trained and untrained humans. American Journal of Physiology, 41, 1258-1263.

[24] Pincemail, J., Camus, G., Roesgen, A., Dreezen, E., Bertrand, Y., Lismonde, M., DebyDupont, G., \&Deby, C. (1990). Exercise induces pentane production and neutrophil activation in humans: effect of propranolol. European Journal of Applied Physiology. 61,319-322.

[25] Sahlin, K., Cizinsky, S., Warholm, M., \& Hoberg, J. (1992). Repetitive static muscle contraction in humans: a trigger of metabolic and oxidative stress. European Journal of Applied Physiology, 64.

[26] Saxton, J. M., Donnelly, A. E., \& Roper, H. P. (1994). Indices of free radical-mediated damage following maximum voluntary eccentric and concentric muscular work. European Journal of Applied Physiology, 68, 189-193.

[27] Sen, C. K., Rankinen, T., Vaisanen, S., \& Rauramaa, R. (1994). Oxidative stress after human exercise: effect of Nacetylcysteine supplementation. J Appl Physiol, 76, 25702577. 
[28] Simpson, R.J., Wilson, M.R., Black, J.R., Ross, J.A., Whyte, G.P., Guy, K. and Florida-James, G.D. (2005). Immune alterations, lipid peroxidation, and muscle damage following a hill race. Canadian Journal of Applied Physiology 30, 196211.

[29] Sumida, S., Tanaka, K., Kiato, H., \&Nakadomo, F. (1989). Exercise-induced lipid peroxidation and leakage of enzymes before and after vitamin $\mathrm{E}$ supplementation. International Journal of Biochemistry, 21(8), 835-838.

[30] Surmen-Gur, E., Ozturk, E., Gur, H., Punduk, Z. and Tuncel, P. (1999) Effect of vitamin E supplementation on post-exercise plasma lipid peroxidation and blood antioxidant status in smokers: with special reference to haemo concentration effect. European Journal of Applied Physiology and Occupational Physiology 79, 472-478.

[31] Verrill, D.E. and Ribisl, P.M. (1996) Resistive exercise training in cardiac rehabilitation. An update. Sports Medicine 21, 347-383.

[32] Viitala, P. E., Newhouse, I. J., LaVoie, N., \& Gottardo, C. (2004). The effects of antioxidant vitamin supplementation on resistance exercise induced lipid peroxidation in trained and untrained participants. Lipids in Health and Disease, 22, 3-14. 